\title{
AN ASSESSMENT OF LAND COVER CHANGE DYNAMICS OF GAJA CYCLONE IN COASTAL TAMIL NADU, INDIA USING SENTINEL 1 SAR DATASET
}

\author{
K. Nivedita Priyadarshini ${ }^{1, *}$, V. Sivashankari ${ }^{1}$, Sulochana Shekhar ${ }^{1}$ \\ ${ }^{1}$ Department of Geography, School of Earth Sciences, Central University of Tamil Nadu, India - nivi.darshini@yahoo.com
}

\author{
ICWG III/IVa
}

KEY WORDS: SAR, Random Forest, Gaja cyclone, speckle filtering, SNAP

\begin{abstract}
:
Land cover change is a dynamic phenomenon addressing environmental issues including natural calamities. Recent advancements in geospatial technology and availability of remote sensor data have fostered monitoring and mapping of land cover changes more precisely. Remote sensing is widely used where emerging research findings are focused mainly on coastal hazard studies. Tropical cyclones being an extreme weather event are more powerful and hazardous to southern parts of the Indian subcontinent. Aftermath of the cyclone is extreme causing land cover changes like defoliation, water logging, destruction of cultivable lands, plantations shrub vegetation, dissolving salt pans etc. The tropical cyclones are fierce to devastate the coastal districts of Tamil Nadu and make it a prey to these cyclones. In this paper, an attempt has been made to assess the pre and post cyclonic land cover change by utilizing potential microwave Synthetic Aperture Radar (SAR) dataset. The study portrays the occurrence of a severe cyclonic storm named 'Gaja' that was formed over Bay of Bengal which hit Tamil Nadu on $15^{\text {th }}$ of November 2018 causing high death toll and demolition. The study focuses on the pre and post damage assessment provoked by Gaja cyclone. For analysis, a methodical procedure was followed by utilizing the Sentinel 1 SAR dataset. Random Forest (RF) classifier approach was incorporated for mapping land cover types as it reduces the variance among the classes thus yielding accurate predictions. Results demonstrate that classified imagery using dual polarization SAR dataset outperforms well for RF classifier thus escalating the overall accuracy.
\end{abstract}

\section{INTRODUCTION}

\subsection{Impact of catastrophic disaster on Land Use}

A drastic increase in population has effectuated people to stay near acute frontiers that are at a verge of calamitous occurrence. Proliferation of migration has led people to extensively utilize natural space and resources causing detriment to the environment (Kron, 2000). For Indian scenario, land suitability analysis plays a vital role as food security is challenged by natural disasters where $12.3 \%, 12 \%$ and $8 \%$ of total population in India is susceptible to flood, drought and cyclone respectively (Kumar et al., 2014 \& Nitheshnirmal et al., 2018). Extreme events like flash floods and cyclonic storms deposits bulks of sand and silt associated with flood water into crop fields thus deteriorating physical composition of fertile soil. Smart and climate adaptive resilient agricultural practices that provide better resistance to crops and plantation during hazardous events will prevail as a colossal scope coping for the near future (UNESCO-IHE, 2009).

Tamil Nadu, one among the Indian states is a major state of victim for at most natural calamities that includes tropical cyclones, tsunami and floods as it borders the Bay of Bengal for 1076 Kilometres. About $8 \%$ of four to five cyclonic storms that occur are very severe along the east coast subjected to heavy down pours with subsequent flooding into dwelling areas and cultivable lands (ENVIS Centre, 2018). Agriculture is the main occupation to the southern districts of Tamil Nadu which is blessed with Cauvery river delta. Traditional cropping patterns like Kuruvai (June - September) and Thaladi (October - January) followed by cultivation of cash crops such as cotton, sugarcane, coconut and banana are predominantly grown (DHDR, 2017). Aftermath of the calamity has a succeeding impact on the existing Land Use / Land Cover (LULC) patterns.

\subsection{Synoptic description of Gaja cyclone}

The present study portrays the occurrence of a severe cyclonic storm named 'Gaja' that was formed over the Bay of Bengal which hit Tamil Nadu on $15^{\text {th }}$ of November 2018 causing high death toll and demolition. Tropical cyclones being an extreme weather event are more powerful and hazardous to the southern parts of the Indian subcontinent. The aftermath of the cyclone is extreme causing land cover changes like defoliation, water logging, destruction of cultivable lands, plantations and shrub vegetation, dissolving salt pans etc. The coastline of Tamil Nadu, forms a major part of the Coromandel coast at the south eastern peninsula of India that extends to a length of about $1076 \mathrm{Km}$ comprising around $15 \%$ of total coastal line length of India. Monsoons are the predominant wind systems of the Indian subcontinent.

The north - east monsoon gives spells of heavy rainfall accompanied by tropical cyclones that emerge from the Bay of Bengal during the months of October and November. By mid October, the low pressure is shifted to the Bay of Bengal making the south - west monsoons to blow out from the mainland towards the sea. The retreating monsoons are off-shore dry winds. As they enter over the Bay of Bengal, they gather moisture and bring considerable rainfall. The north - east monsoon on the Coromandel Coast begins with storms and pours about $48 \%$ of rainfall to Tamil Nadu. The weather becomes unsettled and heavier squalls driving intense rainfall are identified. The tropical cyclones are fierce to devastate the coastal districts of Tamil Nadu and make it a prey to these cyclones.

In general, cyclones are named for better communication between forecasters and the public. Various warning centers in

\footnotetext{
* Corresponding author
} 
south - east Asia provide names to the cyclones originating in the Indian ocean region. Likewise Gaja meaning 'a mighty elephant' in Sanskrit was coined by Sri Lanka. This furious cyclone developed as a mature cyclonic storm towards the coast of Tamil Nadu with a gusting wind speed of about $115 \mathrm{Kmph}$ (IMD, 2018). The Indian Meteorological Department (IMD), a nodal agency for forecasting and publicizing warning has tracked the path of Gaja cyclone from time to time with respect to wind speed and intensity of rainfall in districts of Tamil Nadu. Gaja thrashed the southern coastal tracts namely Vedaranyam of Nagapattinam district, Thiruthuraipoondi and Muthepet of Thiruvarur district, Adirampattinam and Pattukottai of Thanjavur district; Tiruchirappalli, Pudukottai and Dindigul districts of continental location. The trail of Gaja cyclone had left the terrain devoid of vegetation particularly coconut, cashew, mango and plantain grove which were the prime source of economy of the affected victims.

\subsection{LULC with emphasis on Synthetic Aperture Radar}

Remote sensing imageries are used for effective interpretation of land cover changes that are a significant factor in functioning of an ecosystem. Multispectral satellite images provides precise data about the existing landscape as it yields enhanced information with less Ground Sampling Distance (Nivedita et al., 2018). Optical data does not favor all the time rendering cloud free imageries. Due to obscured cloud cover, manipulation of optical sensor data was difficult and hence SAR data was opted for potential outcomes as radar energy penetrates clouds to detect land cover features apparently (Balzter et al., 2015). It has been proven to be credible for assessment of land cover change dynamics and vast applications of geospatial technology (Abdikan et al., 2016).

The technical objective of the study is:

- To elucidate the spatial patterns of rainfall distribution with respect to forecast track and intensity of squalls of Gaja cyclone using Google Earth Engine (GEE)

- To assess the pre and post cyclone land cover dispersion by leveraging SAR

- To estimate acreage of distributed land cover to rationalize the deprivation.

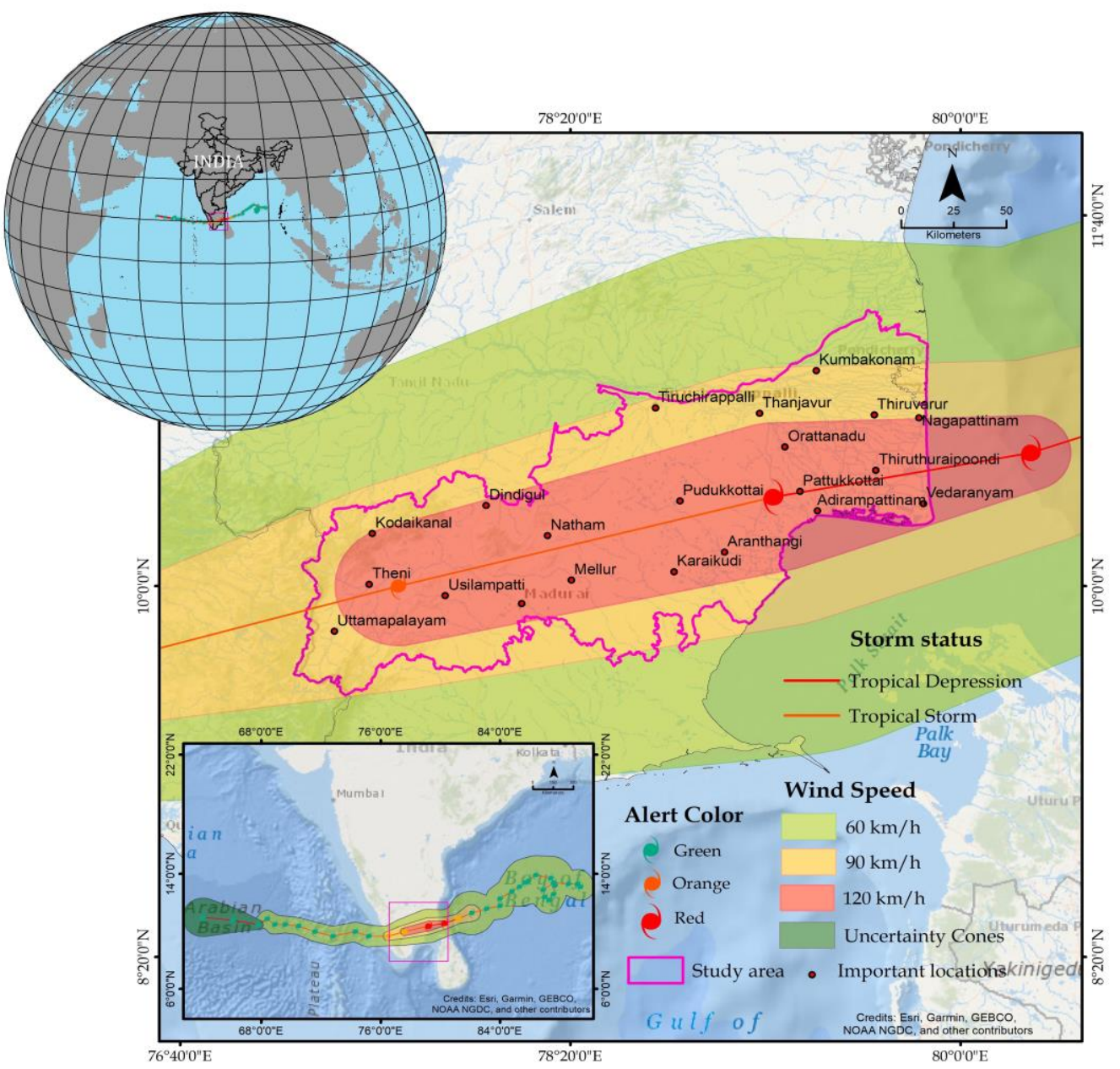

Figure 1. Track of Gaja Cyclone - Associated Coastal districts 


\section{STUDY AREA AND DATASETS}

\subsection{Track of Gaja cyclone}

The southern east coast of Tamil Nadu is historically prone to vigorous tropical cyclones that create intense damage to lives and properties. Gaja was the sixth cyclone among the series of cyclone that hit the coast of Tamil Nadu in 2018 which was initially formed as a low pressure and intensified as a depression over Bay of Bengal. This severe cyclonic storm was reported to cross the coastal districts of Nagapattinam, Thiruvarur and Thanjavur with a wind speed of $100-110 \mathrm{Kmph}$ to $120 \mathrm{Kmph}$ on $15^{\text {th }}$ and $16^{\text {th }}$ of November, 2018.

The coastal and interior parts of these districts covers a total geographical area of $27573.97 \mathrm{Sq}$. Km ranging from an extent of $11^{\circ} 13^{\prime} 12.44^{\prime \prime} \mathrm{N}$ latitude and $79^{\circ} 52^{\prime} 32.78^{\prime \prime} \mathrm{E}$ longitude to $9^{\circ} 31^{\prime} 6.77^{\prime \prime} \mathrm{N}$ latitude and $77^{\circ} 10^{\prime} 11.82$ " E longitude that encountered major devastation (IMD, 2018).

\subsection{Impact of cyclone on land use of the study}

The major occupation of the residing population in the continental districts is agriculture and along the coast is sea salt cultivation and coastal aquaculture. Aftermath of the cyclone, the dwelling communities had to bear the brunt in terms of economic loss. Statistically, about $52 \%$ population in Vedaranyam block, Nagapattinam live in temporary housings of which 26,089 households and 10,512 are semi - kutcha houses that were totally destroyed. Being a hub for perennial crops, $80 \%$ of tree covers over 20 years old have been uprooted in the Cauvery delta region covering Pudukkottai, and Pattukkottai districts, a major coconut belt (The NEWS Minute, 2018). Around, 50 lakh coconut trees were uprooted and each farmer have to wait for a span of another 7 years to restore this loss. Parts of Kodiyakarai, Vedaranyam swamp of Nagapattinam and Muthupet of Thiruvarur district forming state's leading salt manufacturers encountered depletion over 4,000 hectares of salt heaps causing a loss of 3 lakh per salt producer. Officially, 32,000 hectares of nurtured paddy crops and ripe grains ready for harvest were inundated in Adirampattinam of Pattukottai tehsil, Thanjavur district. Nagapattinam which also is a core for jasmine cultivation were destroyed and about 2000 hectares of mango plantations costing 5 years of labour were beaten to ground (The Indian Express, 2018 \& Selvam et al., 2018).

\subsection{Datasets Used}

For this analysis, a methodical procedure was followed by utilizing the Sentinel 1 SAR dataset processed by the European Space Agency (ESA). The level - 1 Ground Range Detected (GRD) product acquired from instrument SAR-C with descending pass direction operated at an Interferometric Wide (IW) swath mode with High Resolution (HR) and with the polarization options $\mathrm{HH}$ or $\mathrm{VV}$ or dual $\mathrm{HH}+\mathrm{HV}$ or $\mathrm{VV}+\mathrm{VH}$ is used. The acquired datasets for both pre and post cyclone studies are processed using Sentinel Application Platform (SNAP) that is designed especially for processing Sentinel data products. For pre and post cyclone land cover assessment data acquired on $8^{\text {th }}$ November 2018 and $20^{\text {th }}$ November 2018 are considered for processing.

The rainfall variability is verified for the study extent using Tropical Rainfall Measuring Mission (TRMM) which is a joint mission of NASA and JAXA rendering gridded data with a spatial resolution of 0.25 degree and a temporal resolution of 3 hours (Earth Engine Data Catalog).

\section{METHODOLOGY}

\subsection{Analysis of rainfall trends using GEE platform}

Google Earth Engine (GEE) is a cloud platform which makes the processing of huge spatial datasets much easier using its highcomputing processes. It consists of a Application Programming Interface (API) through which it can be controlled along with an web-based Interactive Development Environment (IDE) supporting quick visualisation of large processing results (Gorelick et al. 2017). A library of scripts for operating and analysing the open source as well as private data is supported by Earth Engine API. GEE hosts a large number of open source data whose lists can be found in (Gorelick et al. 2017). In recent times, GEE has been adopted and tested for quick processing in various applications of geo-spatial technologies (Dhineshkumar et al. 2019a, 2019b).

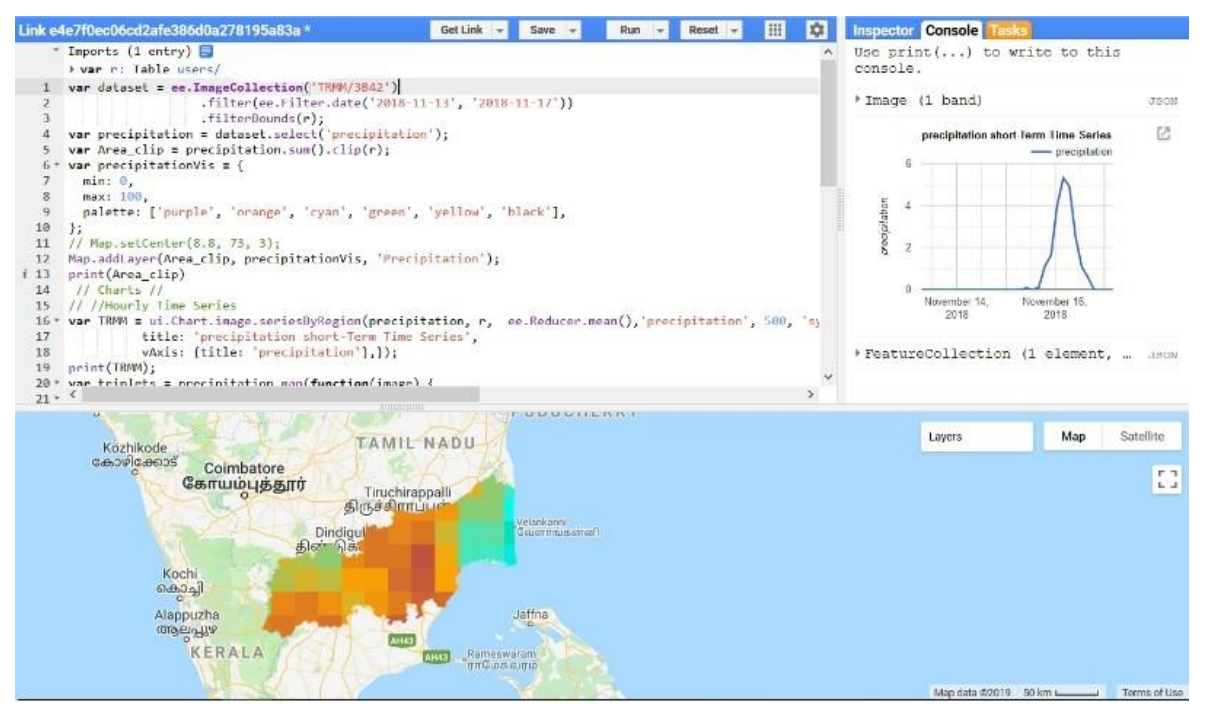

Figure 2. TRMM3B42 from GEE representing the study extent 
In this study, GEE has been utilised to retrieve the amount of rainfall occurred during the Gaja cyclone using TRMM3B42: 3hourly precipitation estimates. During, tropical cyclones heavy precipitation occurs along the path which it travels. Microwave Imager (TMI) is used in TRMM, a passive microwave sensor intended to deliver quantifiable rainfall statistics over a wide swath. The image collection of TRMM3B42 from Earth Engine API along with the below mentioned code (https://code.earthengine.google.com/e4e7f0ec06cd2afe386d0a $278195 \mathrm{a} 83 \mathrm{a}$ ) was used in retrieving the rainfall that occurred during the cyclone. The data of the study area was ingested into the Earth Engine platform and java scripts were used to retrieve the amount of rainfall occurred. The 3-hour rainfall data obtained from GEE was aggregated into a day's rainfall occurrence and it was interpolated using Inverse Distance Weighting (IDW) method.

\subsection{Pre and Post cyclone land cover assessment using SAR}

The Pre and Post cyclonic land use / land cover assessment is interpreted by incorporating the following methodical procedure:

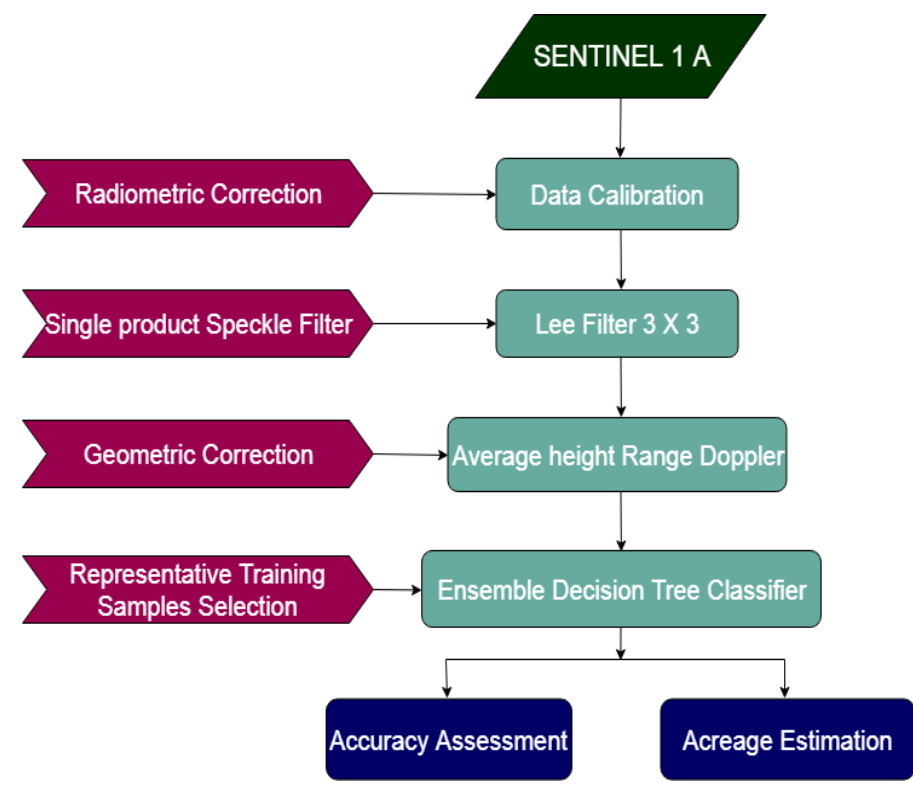

Figure 3. Formulated Workflow

3.2.1 Radiometric correction: The preliminary step in processing of SAR datasets is to perform radiometric calibration in order to associate the pixel values of the imagery with the radar backscatter. The images taken into account exhibits low and high backscatter thus showing dark and bright variations in the imagery due to the effect of cyclone. In order to quantify the changes happened in the ground scene, both the imageries have to be equalised by considering the one representing ample information. It is performed to adjust the gray values depending upon the intensity of the radar backscatter and its phase. Unless the SAR datasets are calibrated, no information can be compared (ESA).

3.2.2 Single product Speckle Filter: Electromagnetic waves though having coherent frequency will not be in phase and minimally reaches the target with numerous backscatter returns from radar pulses thus having a salt-and-pepper granular effect termed as 'speckle' which corrupts the image (Lee et al., 1994). Lee $3 * 3$ filter is applied to suppress the speckle without losing the radiometric calibrated and texture content in the image.

3.2.3 Ellipsoid correction: In general, the all the SAR images are acquired from a definite slant looking geometry. Due to existence of undulated topography, return pulses reaches to the sensor gets distorted causing geometric shift. In order to rectify, Average Height Range - Doppler, an ellipsoidal correction method is applied to the imageries to retain associated pixels in defined location (Step Forum, 2018).
3.2.4 Random forest Classifier: This ensemble decision tree classifier is used for both Classification and Regression Tree (CART). It adds randomness to the data and builds decision trees those bags together to attain maximum accuracy. With respect to the concept of boot strapping, RF yields carts with lower variance (Nivedita et al., 2019). Using the dual polarization ratio a profile is set for the image to obtain the original colour composite in order to collect training datasets for ease of classification. Representative training samples are collected for homogeneous features that are predominantly present in the study area. The prominent classes that are visible and well defined in the SAR dataset are clustered to attain better classification accuracy.

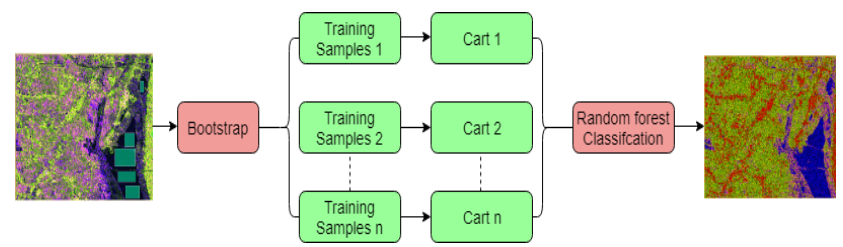

Figure 4. RF Classifier

\section{RESULTS AND DISCUSSION}

\subsection{Interpretation of GEE retrieved results}

From the interpolated results of rainfall taken during the event of Gaja cyclone on $15^{\text {th }}$ and $16^{\text {th }}$ of November 2018 , it can be clearly interpreted that there was an immense down pour affecting the parts of Tamil Nadu from the coasts of Vedaranyam, Nagapattinam district to the inner most part of Uthamapalayam, 
Theni district. It can be observed that the intensity of rainfall decreases as the cyclone trails towards the interior districts of the study area extent. Maximum amount of rainfall is gauged on the day of land fall on $15^{\text {th }}$ November, 2018 which was categorised to be a "cyclonic storm" that had subsequently a higher rate of
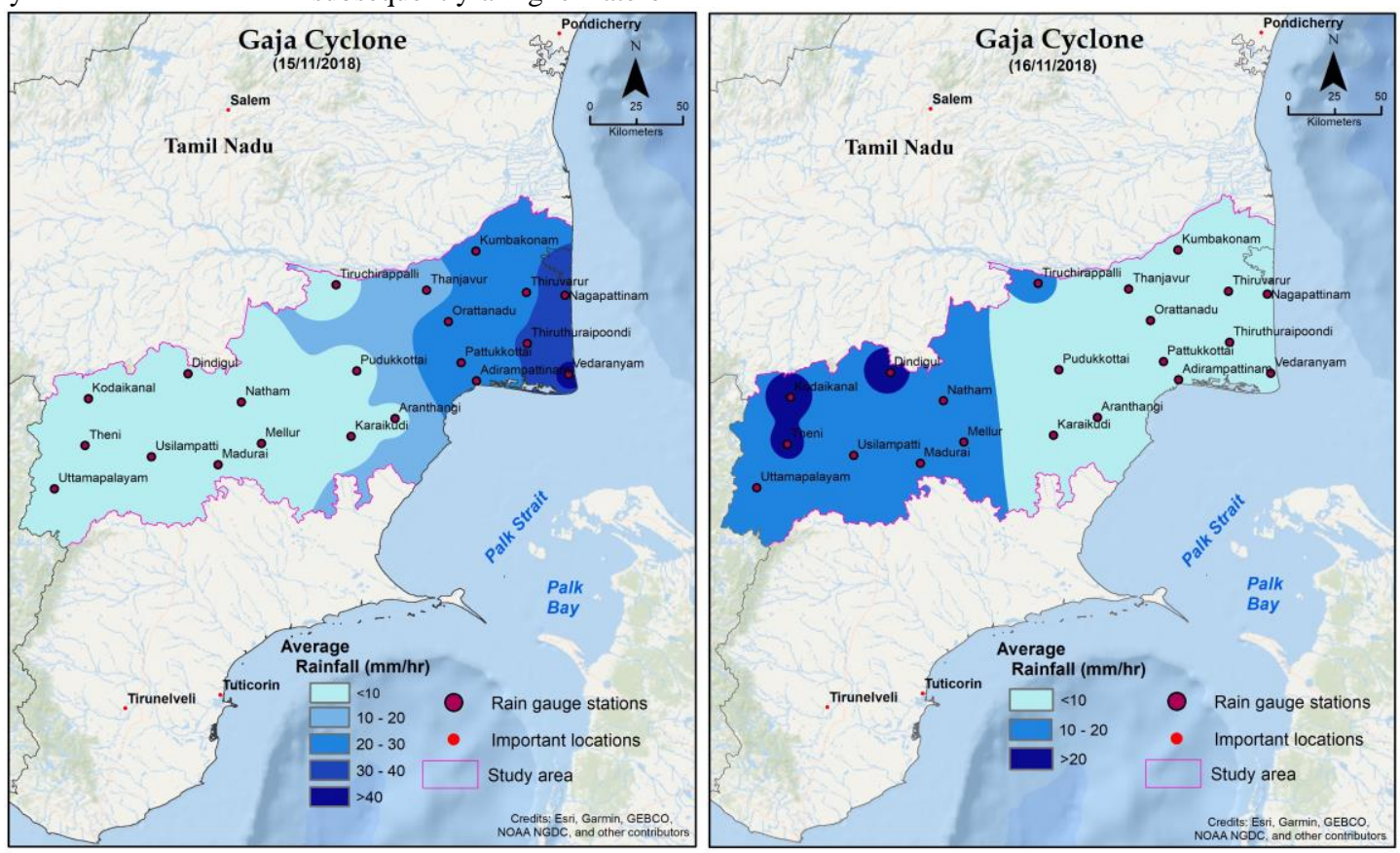

Figure 5. Spatial rainfall distribution during Gaja cyclone

For this study, interpretation of rainfall is remarkably taken as a key component to justify the intensity of rainfall along the track of the cyclone and its subsequent impact on the land use at various regions of Tamil Nadu. The results retrieved from GEE apparently portray the spatial patterns of rainfall variability for the considered study extent.

\subsection{Ensemble classification results of pre and post cyclone land cover}

Significant land cover changes were clearly inferred from the assessment of SAR pre and post cyclone imageries. The land cover of post-cyclone posed a grim threat of the study area that had adorned natural resources. From the classification of pre and post cyclone results, it was inferred that there is an adverse effect on foliage due to the extremity of cyclone. From the dual polarimetric SAR, variable VH is opted for classification as it apparently classifies the given training samples. The classification results chiefly exhibits the decrease in vegetation, mainly cultivation and plantations and inundation of water in salt pans near the coast which were economic sources favouring the rural communities.

\subsection{Acreage estimation}

Form the results generated using SAR, area for each land use feature is estimated to quantify the loss in terms of volume. Most of the land use that were majorly disturbed was vegetation, water inundation in fallow and salt pan swamp areas. Pixel wise count for every land use feature is directly estimated from the classified demolition. However, the amount of rainfall gradually slackened on $16^{\text {th }}$ November, 2018 as the cyclone weakened while moving towards the interior forming a "depression" thus alleviating the damage.

raster dataset. It was observed that, foliage cover comprising of vegetation, paddy cultivation lands, perennial crop plantations, cash crops were totally damaged with $62.5 \%$ of decrease in vegetative cover. As the area of foliage decreases, count of barren land and fallow land subsequently increased by 37 and $44.3 \%$. Water percolated areas of salt pans resulted in dissolving of salt heaps causing substantial spread over a large area and accumulation of sand deposits after cyclone was estimated to be $11.9 \%$. Likewise, LULC features show drastic changes when compared with SAR classified results.

\begin{tabular}{|c|c|c|c|}
\hline LULC & Pre cyclone & $\begin{array}{c}\text { Post } \\
\text { cyclone }\end{array}$ & \% Change \\
\hline Barren Land & 6204 & 8501 & 37.0 \\
\hline Vegetation & 8615 & 3210 & -62.5 \\
\hline Settlements & 6565 & 4977 & -24.0 \\
\hline Water bodies & 2418 & 4111 & 70.0 \\
\hline Fallow Land & 1386 & 2001 & 44.3 \\
\hline $\begin{array}{c}\text { Sand } \\
\text { deposits }\end{array}$ & 1704 & 1907 & 11.9 \\
\hline
\end{tabular}

Table7. Acreage estimation

\subsection{Accuracy assessment}

The results prove that Random Forest outperforms well for SAR imagery classification by escalating the overall accuracy. From the observed outcomes, it is evident that SAR datasets for pre and post cyclone provides a better overall accuracy of $89.74 \%$ and $96.98 \%$ respectively. Further, results can be manipulated for future analysis. 

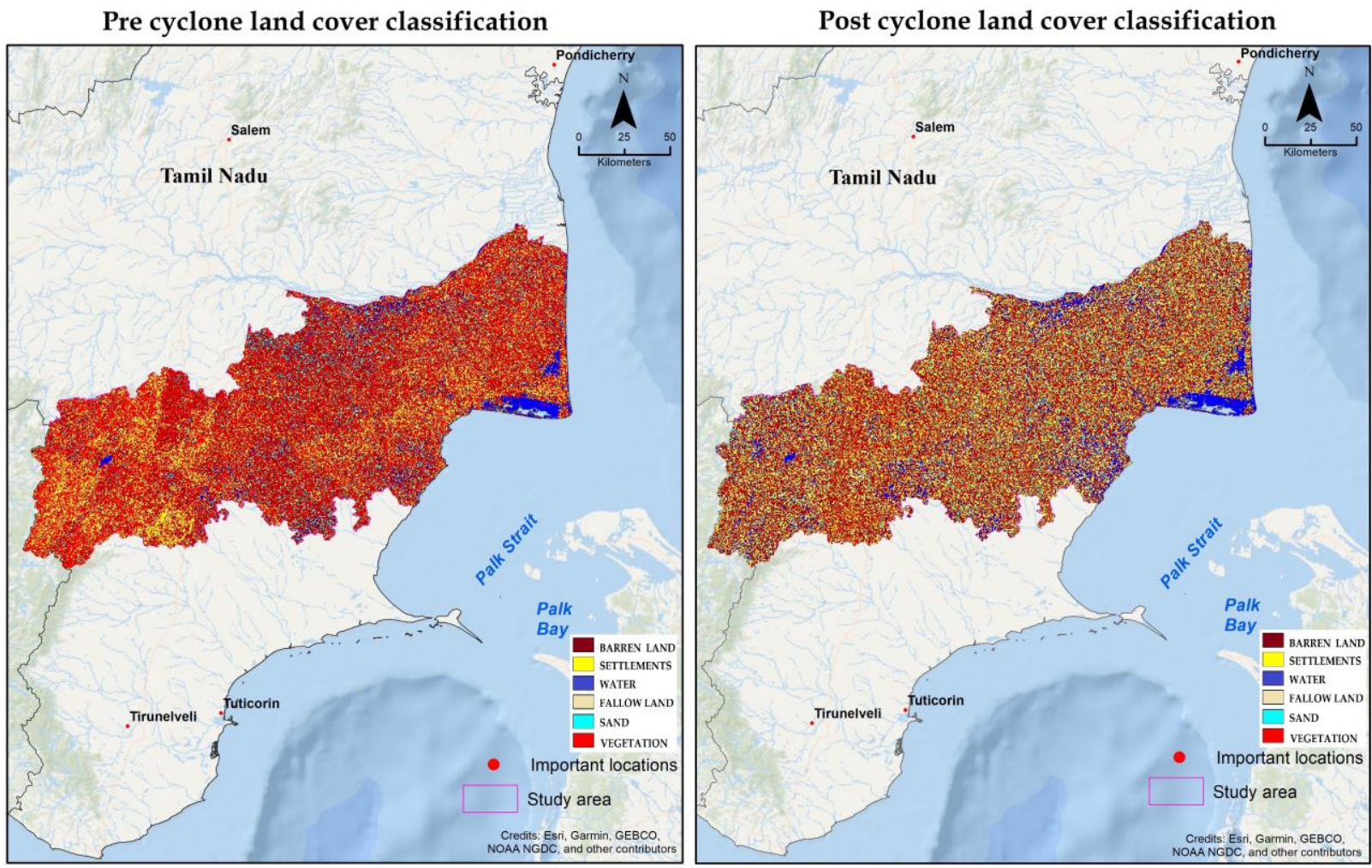

Figure 6. Pre post land cover classification

\section{CONCLUSION}

According to the saying, after a storm comes calm, Gaja had been mighty enough to push the economy of rural population almost 10 years back, leaving trails of sorrow along the coast. Results demonstrate that classified imagery using dual polarization SAR dataset outperforms well for RF classifier thus escalating the overall accuracy. Variation in land cover features are estimated and analyzed for further processing. Evaluation of SAR datasets and computation of area yields precise outcomes than that of incorporating multispectral datasets being a limitation to fulfil the objectives of this study.

\section{REFERENCES}

Abdikan, S., Sanli, F. B., Ustuner, M., and Calò, F., 2016: LAND COVER MAPPING USING SENTINEL-1 SAR DATA, Int. Arch. Photogramm. Remote Sens. Spatial Inf. Sci., XLI-B7, 757761, https://doi.org/10.5194/isprs-archives-XLI-B7-757-2016

Balzter, H., Cole, B., Thiel, C., Schmullius, C., 2015. Mapping CORINE Land Cover from Sentinel-1A SAR and SRTM Digital Elevation Model Data using Random Forests. Remote Sensing, 7, pp. 14876-14898.

Dineshkumar, C., Nitheshnirmal, S., Bhardwaj, A., Nivedita Priyadarshini, K., 2019b. Phenological Monitoring of Paddy crop using Time Series MODIS Data. Proceedings of 2nd International Electronic Conference on Geosciences, 6205. https://doi.org/10.3390/IECG2019-06205

Dineshkumar, C., Satish Kumar, J., Nitheshnirmal, S., 2019a. Rice Monitoring Using Sentinel-1 data in Google Earth Engine Platform. Proceedings of 2nd International Electronic
Conference on Geosciences, https://doi.org/10.3390/IECG2019-06206

District Human Development Report. 2017. State Planning Commission- Tamil Nadu.

ENVIS Centre: Tamil Nadu State of Environment and Related Issues. 2018. DISASTER MANAGEMENT IN TAMIL NADU.

Gorelick, N., Hancher, M., Dixon, M., Ilyushchenko, S., Thau, D., Moore, R., 2017. Google Earth Engine: Planetary-scale geospatial analysis for everyone. Remote Sensing of Environment, 202, https://doi.org/10.1016/j.rse.2017.06.031

K Nivedita, P., Sivashanakri, V., Sulochana, S., \& Balasubramani, K., 2019: Assessment on the potential of multispectral and hyperspectral datasets for Land Use / Land Cover classification. 2nd International Electronic Conference on Geosciences. MDPI. DOI: 10.3390/IECG2019-06211

Kron, W., 2000. Natural Disasters: Lessons from the Past Concerns for the Future. The Geneva Papers on Risk and Insurance, 25 (4), 570 - 581.

Kumar, A., Brahmanand, P., Nayak, A. K., 2014. Management of Cyclone Disaster in Agriculture Sector in Coastal Areas. Directorate of Water Management. Bhubaneswar.

Lee, J. S., Jurkevich, L., Dewaele, P., Wambacq, P., \& Oosterlinck, A., 1994. Speckle filtering of synthetic aperture radar images: A Review. Remote Sensing Reviews, 8 (4). DOI: $10.1080 / 02757259409532206$ 
Level-1 Radiometric Calibration. (n.d.). Retrieved from ESA: https://sentinel.esa.int/web/sentinel/radiometric-calibration-oflevel-1-products

Nitheshnirmal, S., Rahaman, S. A., Balasundareshwaran, A., Nivedita Priyadarshini, K., Balasubramani, K., Kumaraswamy, K, 2018: SPATIO-TEMPORAL ANALYSIS OF NATURAL HUMAN HABITABILITY ENVIRONMENT ALONG THE COASTAL TALUKS OF TAMIL NADU, INDIA, ISPRS Ann. Photogramm. Remote Sens. Spatial Inf. Sci., IV-5, 439-446, https://doi.org/10.5194/isprs-annals-IV-5-439-2018

Nivedita Priyadarshini, K., Kumar, M., Rahaman, S. A., Nitheshnirmal, S., 2018: A COMPARATIVE STUDY OF ADVANCED LAND USE/LAND COVER CLASSIFICATION ALGORITHMS USING SENTINEL-2 DATA, Int. Arch. Photogramm. Remote Sens. Spatial Inf. Sci., XLII-5, 665-670, https://doi.org/10.5194/isprs-archives-XLII-5-665-2018

Retrieved from India Meteorological Department. 2018, November

http://www.imd.gov.in/alerts/20181115_al_627.pdf

Retrieved from The Indian Express. 2018, December 4: https://indianexpress.com/article/india/cyclone-gaja-damagednearly-1-crore-coconut-trees-70000-farmers-hit-tamil-nadu$5477078 /$

Retrieved from The NEWS Minute. 2018, November 18: https://www.thenewsminute.com/article/gaja-effect-thousandscoconut-and-plantain-trees-damaged-lesser-damage-paddy91777

Selvam, V., Velvizhi, S., Gopinath, R., Rajavelan, R., Lakshmanan, P., Nagarajan, R., 2018. Gaja cyclone: Revival of livelihood and restoration of greenery in the coastal areas of Nagapattinam District. MSSRF-Remote Sensing and GIS Unit.

Step Forum. 2018. Retrieved from https://forum.step.esa.int/t/the-reason-of-range-doppler-terraincorrection/12417

TRMM 3B42: 3-Hourly Precipitation Estimates. (n.d.). Retrieved from Earth Engine Data Catalog: https://developers.google.com/earthengine/datasets/catalog/TRMM_3B42

UNESCO-IHE.2009. Flood Vulnerability Indices. Delft, The Netherlands: Institute for Water Education. 